\title{
Implementing smoking bans in American hospitals: results of a national survey
}

\author{
Daniel R Longo, Mary M Feldman, Robin L Kruse, Ross C Brownson, \\ Gregory F Petroski, John E Hewett
}

\begin{abstract}
Objectives-To determine how well hospitals complied with the Joint Commission on Accreditation of Healthcare Organizations (JCAHO) tobacco control standards, which required banning smoking in hospital buildings; to explore issues involved in developing and implementing smoking bans; and to ascertain the perceived success of the policies.

Design-Postal survey conducted January through June 1994.
\end{abstract}

Participants-Stratified random sample of American hospitals surveyed by JCAHO (n = 1055).

Main outcome measures-Enacting smoking policies more restrictive than the JCAHO standard; the respondent's judgment of the relative success of the hospital's smoking policy.

Results-More than $96 \%$ of hospitals complied with the smoking ban standard; $41.4 \%$ enacted policies that were more restrictive than required by JCAHO. Several characteristics were associated with exceeding JCAHO requirements: location in a "non-tobacco state"; having fewer than 100 beds; location in a metropolitan statistical area; having unionised employees; and having no psychiatric or substance abuse unit, favour having the same tobacco policy in psychiatry and substance abuse units as the rest of the hospital. More than $95 \%$ of respondents viewed their hospital's policy as successful. The JCAHO requirements and concern for employees' health were the major forces influencing hospitals to go smoke-free. Negative employee morale and lack of acceptance by visitors and patients were the most commonly cited barriers to overcome when implementing smoke-free policies.

Conclusions-Smoking bans were successfully implemented in American hospitals, with many restricting smoking beyond the JCAHO standard. Other industries wishing to follow hospitals' lead would be most likely to succeed in the context of a social norm favouring a smoking ban and regulation by an outside agency.

(Tobacco Control 1998;7:47-55)

Keywords: smoke-free worksites, hospitals, United States
Introduction

Tobacco use is one of the major causes of death and disease in the United States, accounting for approximately 434000 deaths annually. Secondhand smoke also contributes to this toll, estimated to account for 3800 deaths due to lung cancer and 35000-40000 deaths caused by heart disease ${ }^{2}$ among non-smokers in the United States each year. Annually, employers lose $\$ 50$ billion $^{3}$ in productivity due to smoking in the United States, and the additional expense to employers for each one-packa-day smoker is $\$ 624$ annually. ${ }^{4}$ Some employers have implemented restrictive smoking policies, including total smoking bans, as one way of dealing with the problem.

Hospitals have addressed the issue of workplace smoking by implementing smoking bans. Hospitals are one of the major employers in many American communities, employing approximately 4.3 million individuals nationally. ${ }^{5}$ In 1991 the Joint Commission on Accreditation of Healthcare Organizations (JCAHO) announced tobacco control standards for accredited American hospitals which mandated that they go smoke-free by 31 December 1993. ${ }^{6}$ The tobacco control standards represent a small proportion of the many standards considered by the JCAHO; a given hospital may be non-compliant with the tobacco control standards and still receive accreditation. There are two JCAHO standards on tobacco: the first prohibits smoking within hospitals, whereas the second allows for exceptions to the smoking ban for individual patients based on specific medical criteria. This study addresses the first standard, which requires hospital buildings to be smoke-free.

We conducted a three-phase study to investigate how hospitals were implementing smoking restrictions. In the first phase, we examined data from onsite accreditation surveys conducted by the JCAHO to determine the degree of hospital compliance with tobacco control standards. ${ }^{7}$ Although we found a high degree of compliance with the JCAHO standards, we had little information on other factors involved in the process of becoming smoke-free, such as the degree of employee involvement in developing and implementing policies, policy barriers, and perceptions of the policy's success. Thus, in the second phase of our study we conducted a postal survey to supplement and complement the JCAHO survey data. The third phase of the project involved interviewing employees of smoke-free hospitals and workplaces where smoking was allowed to

\author{
Columbia, Missouri 65212 \\ USA. \\ DanL@fcm.missouri.edu \\ Correspondence to:
Dr DR Longo, Department \\ of Family and Community \\ Medicine, University of \\ Missouri-Columbia \\ Medical Sciences Building,
}


determine the effects of the hospital smoking ban on employee smoking behaviour. ${ }^{8}$ This report presents the findings from phase two of the overall project.

The overall goals of the study were to compare hospitals' smoking policies with the JCAHO standards, to explore issues of policy development and implementation, and to ascertain the perceived effectiveness of the hospitals' smoking policies. Several research questions were addressed: (a) What was the influence of the JCAHO tobacco control standards on the decision of hospitals to implement smoke-free policies? (b) How and to what extent were employees involved in developing and implementing tobacco control policies? (c) What were the major influences in the decision to go smoke-free? (d) What were the major barriers to overcome to implement these policies? and (e) What were the major determinants of successful policies?

\section{Methods}

To elicit information about each of our specific research questions, we developed a 14-item questionnaire in a "closed-end" format. The questionnaire included items on characterising the hospital's smoking policy, employee involvement in a variety of activities before policy implementation, cessation assistance offered before and after policy implementation, the influence of a variety of factors on the process, and an overall rating of policy success. Respondents were given exhaustive lists from which to choose, and had the opportunity to add written responses at the end of the survey. We piloted the questionnaire with 10 hospital chief executive officers (CEOs) selected through a convenience sample.

The questionnaire was revised and then pretested in 40 randomly selected hospitals where it was found that many hospitals had voluntarily exceeded the JCAHO requirement. For example, some hospitals did not permit patient smoking exceptions even though the JCAHO standards permit them. Others prohibited smoking on hospital grounds as well as in the buildings. Consequently, in the final survey instrument, a scale was used to describe more accurately how hospital policies compared with the JCAHO standard. A copy of the final questionnaire is available from the first author on request.

For the final postal survey, we drew a stratified random sample of all American hospitals surveyed by JCAHO. ${ }^{6}$ For the first level of stratification, we divided states into three categories based on acres in tobacco cultivation and level of state tobacco taxation. The six "tobacco states" (Georgia, Kentucky, North Carolina, South Carolina, Tennessee, and Virginia) had greater than $1 \%$ of their arable land in tobacco and a state tax of less than 14 cents per pack. Fifteen "prevention states" (California, District of Columbia, Florida, Iowa, Maine, Maryland, Massachusetts, Minnesota, Nevada, New Jersey, New York, Rhode Island, Texas, Washington, and Wisconsin) had less than $1 \%$ of their arable acreage in tobacco and a tax of at least 34 cents per pack. The remaining 30 states were in a third category, "medium prevention states". We then divided hospitals within the three groups into four approximately equal groups based on number of beds, for a total of 12 strata.

Based on estimates of response and compliance, we required a sample of 1330 hospitals for a $2 \%$ error at the $95 \%$ confidence level (CI). Sample size for each stratum was calculated so that the standard deviation of an estimate was the same across all strata. Hospitals were randomly selected within each stratum to derive the required sample. From 81 to 126 hospitals were selected in each stratum, with 1-121 hospitals in each state.

Questionnaires were mailed to hospital CEOs with a letter of support from the JCAHO president. Individuals most familiar with the hospital's smoking policy were requested to complete the questionnaire. We asked for the position title of the respondent, but did not ask for their smoking status as we were concerned that this would bias their responses; also requested was a copy of their smoking policy with their responses. Military, public health service, and Indian health service hospitals were eliminated from the study because of the substantial differences between these hospitals and most American hospitals on key characteristics such as locus of control. Hospitals were also eliminated if they did not operate or provide services during the study period because of a decision to merge services with another organisational entity (usually another hospital), or to discontinue all operations and services due to actual closure. Notification of such change was made by the American Hospital Association (AHA) membership office and data centre. This reduced the sample to 1283 hospitals.

Surveys were mailed during the last week of January 1994. We used two waves of mailings with reminder postcards to maximise the response rate. We merged survey data with data from the AHA's Annual Survey of Hospitals. ${ }^{9}$ The AHA data provide validated information on a wide variety of hospital organisational characteristics, such as institutional affiliations, workforce description, and ownership. The $\chi^{2}$ statistic was used to assess whether there were differences in several hospital characteristics and survey responses relative to respondent job title.

Data were analysed using sAs statistical software. The $\chi^{2}$ statistic and one-way analyses of variance were used to compare respondents and non-respondents on a variety of categorical and continuous measures, respectively. Frequencies and simple descriptive statistics were computed to characterise smoking policies, implementation procedures, and reported barriers to becoming smoke-free. The $\chi^{2}$ statistic was used to test for associations between level of smoking restriction and hospital characteristics such as size, location, and union status (as reported on the survey); the Mantel-Haenszel $\chi^{2}$ test was used to compare level of compliance with respect to ordinal variables. The odds ratio (OR) and 95\% 
Table 1 Self-reported hospital smoking restrictions compared with the FCAHO smoking ban standard

\begin{tabular}{|c|c|c|c|}
\hline \multicolumn{2}{|c|}{ Smoking policy } & \multirow{2}{*}{$\begin{array}{ll}n & \\
& 28\end{array}$} & \multirow{2}{*}{$\begin{array}{r}\% \\
2.7\end{array}$} \\
\hline 1 & Hospital and grounds are smoke-free, no exceptions allowed (exceeds JCAHO requirements) & & \\
\hline 2 & $\begin{array}{l}\text { Hospital and grounds are smoke-free, exceptions allowed for patients (exceeds JCAHO } \\
\text { requirements) }\end{array}$ & 62 & 5.9 \\
\hline 3 & Hospital building is smoke-free, no exceptions allowed (exceeds JCAHO requirements) & 345 & 32.9 \\
\hline 4 & Hospital building is smoke-free, exceptions allowed for patients (meets JCAHO requirements) & 580 & 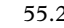 \\
\hline 5 & $\begin{array}{l}\text { Hospital has a plan to go smoke-free, but the plan not implemented (does not meet JCAHO } \\
\text { requirements) }\end{array}$ & 10 & 1.0 \\
\hline 6 & $\begin{array}{l}\text { Hospital wishes to go smoke-free, but there is no plan or target date (does not meet JCAHO } \\
\text { requirements) }\end{array}$ & 15 & 1.4 \\
\hline 7 & Hospital has no plan to go smoke-free (does not meet JCAHO requirements) & 10 & 1.0 \\
\hline \multicolumn{2}{|r|}{ Total (excluding five blank responses) } & 1050 & 100 \\
\hline
\end{tabular}

JCAHO = Joint Commission on Accreditation of Healthcare Organizations.

confidence interval were also calculated to determine the likelihood of exceeding JCAHO requirements given certain hospital characteristics. We employed logistic regression to develop a JCAHO smoking standard compliance model.

\section{Results}

We received surveys from 1055 , or $82.2 \%$, of the recipients. Respondent titles were grouped into several categories: CEO, president, or administrator $(24.7 \%)$; assistant administrator or vice president $(26.9 \%)$; administrators and department heads of human resources $(12.5 \%)$; quality improvement and accreditation personnel (6.7\%); other administrators and department heads (12.7\%); administrative assistants (4.8\%); and all others $(9.5 \%)$. There were no significant differences among groups of respondents $(p>0.05)$ for several variables, including the respondent's satisfaction with the policy, the respondent's perception of the policy's success, location in a tobacco or non-tobacco state, exceeding the requirements of the JCAHO standard, implementing the hospital smoking ban before the JCAHO announcement, perception that there were one or more moderate-to-severe barriers to implementing the smoking ban, or perceived level of employee involvement in planning the smoking ban implementation. However, respondents were more likely to be CEOs for hospitals with less than 100 beds and hospitals in non-metropolitan areas $(\mathrm{p}<0.05)$.

Non-respondents did not differ significantly from hospitals that returned surveys on a wide variety of characteristics, including location in a tobacco state, medium prevention or high prevention state; type of hospital; profit status; bed size; presence of a residency programme; availability of psychiatric services; number of beds dedicated to psychiatric or substance abuse patients; and availability of a variety of services such as worksite health promotion and fitness centres. The only variables found to differ significantly between the two groups $(p<0.05)$ were related to the number of employees. Non-respondents had fewer fulltime employees (mean $=635$ compared with 776 for respondents) and smaller medical staffs (mean $=106$ compared with 133 for respondents). Given the overwhelming number of variables for which the two groups do not differ, we conclude there was no substantial response bias.
Most hospitals were compliant with the ban standard, or exceeded standard requirements (table 1). More than a half $(55.2 \%)$ met the requirements of the standard (level 4 on table 1), $41.4 \%$ exceeded the requirements (levels 1-3 on table 1), and only $3.4 \%$ were not in compliance (levels 5-7 on table 1) as of the date of the survey. We designated hospitals that exceeded the requirements as "highly compliant", those who met the requirements of the standard as "just compliant", and those who did not meet the standard as "non-compliant". Hospitals defined as highly compliant prohibited smoking on the hospital grounds as well as within the building, or allowed no exceptions for individual patients, or both.

We asked respondents to rate the success of their hospital's smoking policy. Most, $60.3 \%$ of respondents, judged their hospital's policy to be very successful, and $36.6 \%$ viewed it as moderately successful. Only $3.3 \%$ indicated the policy was either slightly or not at all successful. The respondent's rating of the success of the policy increased with the restrictiveness of the policy (Mantel-Haenszel $\chi^{2}$ $\mathrm{p}<0.001)$.

JCAHO INFLUENCE

As expected, most (96.7\%) hospitals surveyed had met the smoking standard by 31 December 1993. Unexpectedly, however, most American hospitals implemented smoke-free policies before the JCAHO announced its tobacco control standard. Of the 1020 hospitals that complied with the smoking ban standard, $53.7 \%$ implemented smoke-free policies before the JCAHO announced its tobacco control standard in September 1991.

We predicted that hospitals that went smoke-free before the JCAHO announcement would be more likely to exceed the requirements of the standard. This was not the case. We compared hospitals that enacted their restrictive smoking policies before the JCAHO announcement with those that enacted bans after the announcement by calculating the odds ratio and $95 \%$ confidence interval for high compliance. There was no association between high compliance and policy enactment before the JCAHO announcement $(\mathrm{OR}=1.06,95 \% \mathrm{CI}=0.82$ to 1.39$)$. Involvement of employees in policy-related activities before enactment, presence of a union, hospital size, location in a metropolitan statistical area, 
Table 2 Respondents' report of employee involvement in various activities before hospital's enactment of smoke-free policy

\begin{tabular}{lllllll}
\hline Activity & $\begin{array}{l}\text { Activity not } \\
\text { offered } \\
n(\%)\end{array}$ & $\begin{array}{l}\text { Not involved } \\
\text { at all } \\
n(\%)\end{array}$ & $\begin{array}{l}\text { Slightly } \\
\text { involved } \\
n(\%)\end{array}$ & $\begin{array}{l}\text { Moderately } \\
\text { involved } \\
n(\%)\end{array}$ & $\begin{array}{l}\text { Very } \\
\text { involved } \\
n(\%)\end{array}$ & $\begin{array}{l}\text { Mean } \\
\text { involvement } \\
n(\%)\end{array}$ \\
\hline Received smoking cessation materials & $102(10.2)$ & $46(4.6)$ & $179(17.9)$ & $347(34.7)$ & $325(32.5)$ & 2.7 \\
Served on planning committee(s) & $193(19.2)$ & $110(10.9)$ & $126(12.5)$ & $217(21.5)$ & $361(35.8)$ & 2.4 \\
Reviewed policy drafts & $166(16.7)$ & $148(14.9)$ & $152(15.3)$ & $251(25.2)$ & $279(28.0)$ & 2.3 \\
Attended smoking cessation programmes & $124(12.5)$ & $69(6.9)$ & $324(32.6)$ & $323(32.5)$ & $155(15.6)$ & 2.3 \\
Participated in "cold turkey" days & $175(17.6)$ & $97(9.7)$ & $269(27.0)$ & $283(28.4)$ & $172(17.3)$ & 2.2 \\
Received planning committee reports & $243(24.5)$ & $147(14.8)$ & $137(13.8)$ & $208(21.0)$ & $255(25.8)$ & 2.1 \\
Participated in employee surveys & $332(33.9)$ & $150(15.3)$ & $79(8.1)$ & $165(16.9)$ & $253(25.8)$ & 1.8 \\
Involved as peer counsellors & $384(38.9)$ & $221(22.4)$ & $180(18.3)$ & $140(14.2)$ & $61(6.2)$ & 1.3 \\
\hline
\end{tabular}

*Activities are ranked from highest to lowest mean involvement, with "Activity not offered" $=0$ and "Very involved" $=4$.

and location in a tobacco state were similarly unrelated to whether a hospital enacted its policy before or after the JCAHO announcement. Respondents who perceived the existence of one or more substantial barriers to policy implementation were more likely to come from hospitals that enacted policies after the JCAHO announcement $(\mathrm{OR}=1.50,95 \%$ $\mathrm{CI}=1.15$ to 1.96$)$.

\section{EMPLOYEE INVOLVEMENT}

We expected hospitals to have included their employees in activities involving the tobacco control policy before implementing the smoking ban. Table 2 summarises means of reported employee involvement. Respondents most frequently reported that employees were moderately to very involved in receiving smoking cessation materials (67.2\%). The lowest participation rate was reported for peer counselling, with reported employee involvement of $20 \%$. Notably, more than a half of respondents reported substantial employee involvement on planning committees.

Four of the eight reported activities offered to employees before smoke-free policy enactment - serving on planning committees, receiving planning committee reports, reviewing policy drafts, and participating in employee surveys-were most directly involved with policy development (table 2 ). Just over $30 \%$ of respondents reported less than moderate employee involvement in any of these planning activities, $24.3 \%$ reported moderate-to-high involvement in all four planning activities, $19.5 \%$ in three, $11.0 \%$ in two, and $14.7 \%$ in only one. Respondents who reported that hospital employees were involved in one or more planning activities were no more likely to be highly compliant $(\mathrm{OR}=1.04,95 \% \mathrm{CI}=0.79$ to 1.36), but were perceived as having more successful tobacco control policies $(\mathrm{OR}=$ $2.34,95 \% \mathrm{CI}=1.04$ to 5.26 ).
Most respondents reported that their hospitals $(91.1 \%)$ provided some type of smoking cessation assistance to employees (table 3). There was considerable diversity in how useful the various types of assistance would be to smokers. For example, signs posted in the institution would not be as helpful as individual counselling or nicotine patches. We examined the most substantial cessation assistance activities more closely: individual counselling, cessation classes or groups, nicotine patches, hypnosis, and nicotine gum. Most hospitals (77.8\%) provided at least one of these, $1.6 \%$ provided all five and $21.4 \%$ provided three or four. Hospitals that reported providing one or more substantial cessation activities were not more likely to be highly compliant $(\mathrm{OR}=0.92,95 \% \mathrm{CI}=0.68$ to $1.24)$ or to have respondents rate the smoking policy as more successful ( $\mathrm{OR}=1.18,95 \%$ $\mathrm{CI}=0.46$ to 3.01 ). Respondents who reported that employee health was either a moderate or very important influence in the hospital's decision to go smoke-free were more likely to report one or more types of substantial assistance than those who rated employee health as either a slight or insignificant influence $(\mathrm{OR}=2.47,95 \% \mathrm{CI}=1.64$ to 3.74$)$.

\section{INFLUENCES IN THE DECISION TO GO}

SMOKE-FREE

Respondents reported that hospitals were likely to be influenced by a combination of internal and external factors in their decision to go smoke-free (table 4). External influences included such factors as laws or regulations and public image, whereas internal influences included concern for employee health, cost savings, fire safety, and employee pressure. Most respondents $(96.7 \%)$ reported that a combination of internal and external factors influenced the hospital's decision to go smokefree. The JCAHO standard was a dominant

Table 3 Hospitals reported to offer each type of assistance for smoking cessation

\begin{tabular}{lcccc}
\hline Type of assistance & $\begin{array}{l}\text { Not offered } \\
n(\%)\end{array}$ & $\begin{array}{l}\text { During policy } \\
\text { phase-in } \\
n(\%)\end{array}$ & $\begin{array}{l}\text { After policy } \\
\text { phase-in } \\
n(\%)\end{array}$ & $\begin{array}{l}\text { During and } \\
\text { after phase-in } \\
n(\%)\end{array}$ \\
\hline Signs posted in the institution & $357(33.8)$ & $120(11.4)$ & $122(11.6)$ & $456(43.2)$ \\
Books, articles, or pamphlets & $497(47.1)$ & $123(11.7)$ & $64(6.1)$ & $371(35.2)$ \\
Smoking cessation classes/groups free of charge & $513(48.6)$ & $181(17.2)$ & $82(7.8)$ & $279(26.4)$ \\
Initial provision of smoking areas during policy phase-in & $585(55.5)$ & $237(22.5)$ & $60(5.7)$ & $173(16.4)$ \\
Individual counselling & $693(65.7)$ & $93(8.8)$ & $59(5.6)$ & $210(19.9)$ \\
Smoking cessation classes/groups at reduced price & $735(69.7)$ & $52(4.9)$ & $119(11.3)$ & $149(14.1)$ \\
Nicotine patch at reduced price & $807(76.5)$ & $24(2.3)$ & $106(10.0)$ & $118(11.2)$ \\
Videos & $809(76.7)$ & $40(3.8)$ & $37(3.5)$ & $169(16.0)$ \\
Nicotine gum at reduced price & $925(87.7)$ & $9(0.9)$ & $40(3.8)$ & $81(7.7)$ \\
Nicotine patch free of charge & $961(91.1)$ & $29(2.7)$ & $29(2.7)$ & $36(3.4)$ \\
Hypnosis & $995(94.3)$ & $13(1.2)$ & $11(1.0)$ & $36(3.4)$ \\
Nicotine gum free of charge & $1018(96.5)$ & $13(1.2)$ & $7(0.7)$ & $17(1.6)$ \\
\hline
\end{tabular}


Table 4 Respondents' rating of the influence of various factors on the hospital's decision to go smoke-free

\begin{tabular}{|c|c|c|c|c|c|}
\hline Factor & $\begin{array}{l}\text { Did not } \\
\text { influence at all } \\
n(\%)\end{array}$ & $\begin{array}{l}\text { Slight } \\
\text { influence } \\
n(\%)\end{array}$ & $\begin{array}{l}\text { Moderate } \\
\text { influence } \\
n(\%)\end{array}$ & $\begin{array}{l}\text { Very } \\
\text { important } \\
\text { influence } \\
n(\%)\end{array}$ & $\begin{array}{l}\text { Mean } \\
\text { influence* } \\
n(\%)\end{array}$ \\
\hline \multicolumn{6}{|l|}{ External influences } \\
\hline JCAHO requirement & $137(13.9)$ & $79(8.0)$ & $166(16.8)$ & $605(61.3)$ & 3.4 \\
\hline Public image & $85(8.6)$ & $154(15.5)$ & $325(32.8)$ & $427(43.1)$ & 3.1 \\
\hline EPA report on secondhand smoket & $276(28.7)$ & $216(22.5)$ & $287(29.8)$ & $183(19.0)$ & 2.4 \\
\hline State law/regulation & $404(42.4)$ & $141(14.8)$ & $152(15.9)$ & $256(26.9)$ & 2.3 \\
\hline Patient pressure & $367(38.5)$ & $325(34.1)$ & $193(20.3)$ & $68(7.1)$ & 2.0 \\
\hline Other professional organisation guidelines & $444(57.6)$ & $119(15.4)$ & $117(15.2)$ & $91(11.8)$ & 1.8 \\
\hline Local or municipal law/regulation & $585(62.3)$ & $106(11.3)$ & $132(14.1)$ & $116(12.4)$ & 1.8 \\
\hline \multicolumn{6}{|l|}{ Internal influences } \\
\hline Concern for the health of employees & $27(2.7)$ & $89(9.0)$ & $282(28.4)$ & $594(59.9)$ & 3.4 \\
\hline Fire safety & $127(13.0)$ & $245(25.1)$ & $297(30.5)$ & $306(31.4)$ & 2.8 \\
\hline Employee pressure & $271(27.9)$ & $335(34.5)$ & $283(29.2)$ & $81(8.4)$ & 2.2 \\
\hline Cost savings & $391(41.0)$ & $262(27.5)$ & $201(21.1)$ & $99(10.4)$ & 2.0 \\
\hline
\end{tabular}

*Activities are ranked from highest to lowest mean influence within each category, with "Did not influence at all" $=1$ and "Very important influence" $=4$.

JCAHO = Joint Commission on Accreditation of Healthcare Organizations.

†US Environmental Protection Agency. Respiratory health effects of passive smoking: lung cancer and other disorders. Washington, DC: EPA, 1992. (EPA/600/6-90/006F.)

force influencing hospitals to go smoke-free, along with "concern for the health of employees". Both factors were scored by approximately $60 \%$ of respondents as "very important influences" in the decision to go smoke-free.

Sixty per cent of all compliant hospitals reported that three to six of the above factors had a moderate-to-very important influence in their decision to implement a smoke-free policy, with a median response of four. Having four or more influences cited by respondents was not predictive of either high compliance $(\mathrm{OR}=1.21,95 \% \mathrm{CI}=0.92$ to 1.61$)$ or the reported success of the policy $(\mathrm{OR}=1.64$, $95 \% \mathrm{CI}=0.71$ to 3.80 ).

\section{BARRIERS TO IMPLEMENTING A SMOKE-FREE} POLICY

We hypothesised that the barriers hospitals that had to overcome to implement their smoke-free policies were more likely to be a combination of internal and external factors than either type of factor alone (table 5). Internal barriers included factors such as negative employee morale and lack of physician support, whereas external barriers included union contract restrictions and lack of acceptance by patients, visitors, or the community. Respondents from compliant hospitals were asked to report on difficulties they encountered while implementing their tobacco control policy, whereas respondents from noncompliant hospitals reported on barriers that affected their ability to enact such a policy. Approximately $6 \%$ of respondents reported only external barriers to going smoke-free, $16 \%$ reported only internal barriers, and approximately $79 \%$ of hospitals reported being affected by both external and internal barriers.

Very few barriers were perceived as severe, with lack of patient acceptance being cited most frequently, by $5 \%$. The factors most frequently reported as moderate barriersnegative employee morale, lack of patient acceptance, and lack of visitor acceptancewere each cited by just over $20 \%$ of respondents. Union contract restrictions were rarely reported.

Just under half of the respondents $(46.3 \%)$ reported having no major (moderate-to-severe) barriers to policy implementation, $22.8 \%$ reported one, and $13.9 \%$ reported two. Only $3 \%$ perceived five or more barriers to going smoke-free. Hospitals with no major barriers were no more likely to be highly compliant than those with one or more barriers $(\mathrm{OR}=$ $1.09,95 \% \mathrm{CI}=0.85$ to 1.39 ), but respondents were more likely to view these hospitals' policies as successful $(\mathrm{OR}=7.01,95 \% \mathrm{CI}=$ 2.46 to 20.0 ).

MAJOR DETERMINANTS OF SUCCESS

Our initial intention was to determine what distinguished hospitals whose smoking policies met JCAHO standards from those that did not. So few hospitals were non-compliant that it was impossible to develop reliable predictors of compliance. Rather than modelling compliance, we looked at variables associated with highly compliant $v s$ just compliant hospitals.

Table 5 Respondents' ratings of perceived barriers to implementing smoke-free policies

\begin{tabular}{|c|c|c|c|c|c|}
\hline Potential barrier & $\begin{array}{l}\text { No barrier at } \\
\text { all } \\
n(\%)\end{array}$ & $\begin{array}{l}\text { Slight barrier } \\
n(\%)\end{array}$ & $\begin{array}{l}\text { Moderate } \\
\text { barrier } \\
n(\%)\end{array}$ & $\begin{array}{l}\text { Severe } \\
\text { barrier } \\
n(\%)\end{array}$ & $\begin{array}{l}\text { Mean } \\
\text { rating* } \\
n(\%)\end{array}$ \\
\hline \multicolumn{6}{|l|}{ Internal barriers } \\
\hline Negative employee morale & $194(18.6)$ & $590(56.5)$ & $236(22.6)$ & $25(2.4)$ & 2.1 \\
\hline Reduced employee productivity & $471(45.5)$ & $410(39.6)$ & $145(14.0)$ & $10(1.0)$ & 1.7 \\
\hline Lack of physician support & $736(71.4)$ & $215(20.9)$ & $69(6.7)$ & $11(1.1)$ & 1.4 \\
\hline Inadequate availability of cessation programmes & $769(75.4)$ & $175(17.2)$ & $71(7.0)$ & $5(0.5)$ & 1.3 \\
\hline \multicolumn{6}{|l|}{ External barriers } \\
\hline Lack of patient acceptance & $294(28.3)$ & $464(44.6)$ & $231(22.2)$ & $51(4.9)$ & 2.0 \\
\hline Lack of visitor acceptance & 337 (32.5) & 449 (43.3) & $211(20.3)$ & $40(3.9)$ & 2.0 \\
\hline Lack of community support & $755(73.3)$ & $210(20.4)$ & $55(5.3)$ & $10(1.0)$ & 1.3 \\
\hline Union contract restrictions & $918(93.7)$ & $38(3.9)$ & $14(1.4)$ & $10(1.0)$ & 1.1 \\
\hline
\end{tabular}

^Activities are ranked from highest to lowest mean rating within each category, with "No barrier at all" = 1 and "Severe barrier" $=4$. 
Table 6 Relationship between selected hospital characteristics and the likelihood of restricting smoking beyond the requirements of the FCAHO smoking ban standard

\begin{tabular}{|c|c|c|c|}
\hline Hospital characteristic & $\begin{array}{l}\text { Total number } \\
\text { of hospitals }\end{array}$ & $\begin{array}{l}\% \text { Exceeding } \\
\text { standard }\end{array}$ & $\begin{array}{l}\text { Odds ratio } \\
(95 \% \mathrm{CI})\end{array}$ \\
\hline Located in a non-tobacco-growing state & 759 & 49.0 & $2.94(2.14-4.05)$ \\
\hline Located in metropolitan statistical area & 694 & 45.5 & $1.41(1.08-1.85)$ \\
\hline No moderate-to-severe barriers to policy implementation & 485 & 43.9 & $1.08(0.85-1.39)$ \\
\hline $\begin{array}{l}\text { Employees moderately to very involved in one or more of first } 4 \text { planning } \\
\text { activities }\end{array}$ & 705 & 43.1 & $1.04(0.79-1.36)$ \\
\hline \multicolumn{4}{|l|}{ Type of ownership } \\
\hline Not-for-profit & 593 & 55.6 & Referent \\
\hline State/local government & 192 & 43.2 & $0.96(0.69-1.33)$ \\
\hline For profit & 200 & 40.0 & $0.84(0.60-1.16)$ \\
\hline Federal government & 29 & 31.0 & $0.56(0.25-1.26)$ \\
\hline \multicolumn{4}{|l|}{ Type of hospital } \\
\hline Children's hospital & 18 & 94.4 & Referent \\
\hline General hospital & 851 & 40.9 & $0.04(0.005-0.31)$ \\
\hline Psychiatric and chemical/alcohol dependency & 93 & 49.5 & $0.06(0.007-0.45)$ \\
\hline Other specialty & 52 & 46.1 & $0.05(0.006-0.41)$ \\
\hline Less than 100 beds & 308 & 52.0 & $1.74(1.32-2.29)$ \\
\hline \multicolumn{4}{|l|}{ Psychiatric unit } \\
\hline No unit in hospital & 504 & 46.2 & Referent \\
\hline Unit with same policy as hospital & 242 & 57.8 & $1.60(1.17-2.18)$ \\
\hline Unit with less restrictive policy & 222 & 21.2 & $0.31(0.22-0.45)$ \\
\hline No dedicated psychiatric beds & 550 & 46.2 & $1.40(1.08-1.82)$ \\
\hline \multicolumn{4}{|l|}{ Substance abuse unit } \\
\hline No unit in hospital & 634 & 44.5 & Referent \\
\hline Unit with same policy as hospital & 184 & 56.5 & $1.62(1.17-2.26)$ \\
\hline Unit with less restrictive policy & 141 & 20.6 & $0.32(0.21-0.50)$ \\
\hline No dedicated alcohol/chemical dependency beds & 764 & 44.1 & $1.33(0.96-1.85)$ \\
\hline Cancer programme approved by American College of Surgeons & 252 & 42.5 & $0.98(0.73-1.30)$ \\
\hline Affiliation with an LCME-accredited medical school & 212 & 43.4 & $1.03(0.76-1.39)$ \\
\hline Hospital has unionised employees & 240 & 53.3 & $1.74(1.30-2.33)$ \\
\hline \multicolumn{4}{|l|}{ Hospital programmes } \\
\hline Community health promotion & 789 & 42.4 & $0.94(0.67-1.32)$ \\
\hline Chronic obstructive pulmonary disease services & 652 & 43.1 & $1.05(0.80-1.38)$ \\
\hline Fitness centre & 236 & 43.6 & $1.05(0.78-1.41)$ \\
\hline Patient education programme & 861 & 43.3 & $1.29(0.83-2.00)$ \\
\hline Worksite health promotion & 637 & 43.1 & $1.04(0.79-1.36)$ \\
\hline Medical or dental residency & 219 & 46.1 & $1.18(0.88-1.60)$ \\
\hline \multicolumn{4}{|l|}{ Psychiatry services available } \\
\hline Child psychiatric services & 321 & 42.1 & $0.96(0.73-1.26)$ \\
\hline Consulting & 488 & 41.6 & $0.91(0.70-1.18)$ \\
\hline Education & 350 & 41.1 & $0.90(0.69-1.18)$ \\
\hline Emergency & 520 & 41.7 & $0.92(0.71-1.18)$ \\
\hline Geriatric & 377 & 40.6 & $0.86(0.66-1.13)$ \\
\hline Outpatient & 373 & 42.6 & $0.99(0.76-1.29)$ \\
\hline Subsidiary unit & 15 & 20.0 & $0.33(0.09-1.18)$ \\
\hline 3-7 psychiatry services (vs $0-2$ ) & 395 & 40.2 & $0.84(0.65-1.09)$ \\
\hline
\end{tabular}

JCAHO = Joint Commission on Accreditation of Healthcare Organizations; LCME = Liaison Committee on Medical Education;

$\mathrm{CI}=$ confidence interval.

We considered several variables as possible determinants of high compliance, including greater employee participation in policy development, fewer barriers to implementing a smoke-free policy, limited psychiatric or substance abuse services, and hospital characteristics that were found to be predictive of compliance with the JCAHO smoking ban standard (table 6). ${ }^{7}$ Several variables were associated with a greater likelihood of high compliance: location in a non-tobacco growing state, location in a metropolitan statistical area (MSA), having fewer than 100 beds, having no dedicated psychiatry beds, being a children's hospital, and employee unionisation. Type of ownership and services available were not related to exceeding the requirements of the JCAHO standard.

Respondents were asked whether their hospitals had psychiatric or substance abuse units and, if so, whether they had less restrictive smoking policies than did the rest of the hospital. Almost a half of the respondents reported having a psychiatric unit, and approximately a third had substance abuse units. Hospitals whose psychiatric units had the same smoking policy as the rest of the hospital were more likely to be highly compliant than hospitals without psychiatric units $(\mathrm{OR}=$
1.60). Hospitals with a less restrictive smoking policy in their psychiatric unit were less likely to be highly compliant than hospitals without units $(\mathrm{OR}=0.31)$. Smoking policies in substance abuse units were similarly related to high compliance (table 6). Neither the presence of a psychiatric or substance abuse unit, nor the type of smoking policy within that unit was related to the success of the policy according to the respondent.

We used logistic regression to develop a model of high compliance, initially using all variables that were significant predictors in bivariate analyses. The final regression model is shown in table 7. Variables that predicted high compliance include (a) location in a nontobacco state; (b) fewer than 100 beds; (c) unionised employees; (d) location in a metropolitan area; (e) no psychiatry or substance abuse unit present; and (f) presence of a psychiatry or substance abuse unit with the same policy as the rest of the hospital (hospitals with a psychiatry or substance abuse unit with a less restrictive policy scored 0 for items 5 and 6).

Consistent with the bivariate analyses (table 6), the children's hospital variable had a high odds ratio in the logistic model $(\mathrm{OR}=14.5)$. However, there were only 18 children's 
Table 7 Logistic models of major determinants for hospitals to enact more restrictive smoking policies than required by the FCAHO smoking ban standard

\begin{tabular}{|c|c|c|c|c|}
\hline \multirow[b]{2}{*}{ Variable } & \multicolumn{2}{|c|}{ Initial model with all variables } & \multicolumn{2}{|l|}{ Final model } \\
\hline & $\begin{array}{l}\text { Odds ratio } \\
(95 \% \mathrm{CI})\end{array}$ & $p$ & $\begin{array}{l}\text { Odds ratio } \\
(95 \% \mathrm{CI})\end{array}$ & $p$ \\
\hline Non-tobacco state & $2.75(1.91-3.96)$ & 0.0001 & $2.70(1.88-3.86)$ & 0.0001 \\
\hline Metropolitan location & $1.48(1.05-2.07)$ & 0.0237 & $1.56(1.12-2.18)$ & 0.0090 \\
\hline Unionised & $1.72(1.22-2.42)$ & 0.0022 & $1.70(1.20-2.39)$ & 0.0026 \\
\hline Fewer than 100 beds & $1.81(1.29-2.55)$ & 0.0006 & $1.91(1.37-2.68)$ & 0.0002 \\
\hline No psychiatry or substance abuse unit & $2.35(1.33-4.15)$ & 0.0032 & $2.89(1.96-4.26)$ & 0.0001 \\
\hline Psychiatry or substance abuse unit with same policy as hospital & $4.41(2.90-6.69)$ & 0.0001 & $4.76(3.15-7.20)$ & 0.0001 \\
\hline Children's hospital & $14.5(1.88-111)$ & 0.0103 & NA & NA \\
\hline No dedicated psychiatric beds & $1.25(0.75-2.08)$ & 0.3991 & NA & NA \\
\hline$c$-statistic & 0.73 & NA & 0.72 & NA \\
\hline Goodness-of-fit ${ }^{\star}$ & 13.3 & 0.06 & 11.5 & 0.17 \\
\hline
\end{tabular}

^Non-significant value implies acceptable model fit.

$\mathrm{JCAHO}=$ Joint Commission on Accreditation of Healthcare Organizations; NA $=$ not applicable.

hospitals in our sample, 17 of which were highly compliant, leading to the wide confidence interval shown in table 7 . Leaving the children's hospital variable out of the model had little effect on either the $c$-statistic or the odds ratios of the other variables, and it improved the overall fit of the model. The variable representing dedicated psychiatry beds was not significant when the presence of psychiatry or substance abuse units and the type of policy in these units was incorporated into the model.

\section{Discussion}

Most American hospitals complied with the JCAHO smoking ban standard, and many even exceeded the requirements of the standard. This may indicate that workplace smoking restrictions may be successfully implemented. More than $90 \%$ of the administrators responding to the survey judged their hospital's policy to be moderately to very successful.

JCAHO INFLUENCE

More than half of the hospitals surveyed implemented smoke-free policies before the JCAHO announcement of its tobacco control standards. This suggests there was a growing professional consensus toward workplace smoking restriction before the announcement. The JCAHO captured this sentiment with the enactment of a smoke-free requirement. Although a professional consensus developed before the standard, the JCAHO served as a final catalyst for policy implementation. This concept could extend to other industries where smoking bans are regarded as social norms. For example, although the social norm in bars or nightclubs would be resistant to a smoking ban, the norm in many restaurants, pharmacies, movie theatres, for example, would be favourable to smoking bans. ${ }^{10}$ Additionally, a regulatory agency capable of implementing such a ban may provide the necessary impetus; requiring organisations to be smoke-free may be integral to realising the final step in the process.

Of the 1015 compliant hospitals, $43 \%$ exceeded JCAHO requirements. There was no association between the year of enacting the smoke-free policy relative to the JCAHO requirement and the level of compliance with the standard. This indicates there was no pro- gression in the restrictiveness of policies over time. Rather, it appears that hospitals implemented their "final" policy at one distinct point in time. Sorensen and associates report that total bans may be put in place more successfully than less restrictive policies. ${ }^{11}$ However, some authors have noted difficulties with compliance or morale. ${ }^{12-15}$ Hospitals that were inclined to be more restrictive in their smoking bans exceeded JCAHO standards from the outset, rather than increasing restrictions over time. They did not, however, implement their policies earlier than other hospitals.

\section{EMPLOYEE INVOLVEMENT}

Respondents reported that employees were involved in activities pertaining to tobacco control before smoking ban enactment in most hospitals. Only $13 \%$ of respondents indicated little or no employee involvement in the activities listed on our survey. However, hospitals with greater employee involvement in planning activities were perceived by administrators as having more successful policies. Logically, greater involvement in the planning process gives employees a greater sense that their concerns are important and contributes to successful policy implementation.

Although most hospitals provided some type of smoking cessation assistance to employees, the amount and types of assistance were not related to either the level of compliance or the level of perceived success. Hospitals that reported that "concern for the health of employees" was a major influence in the decision to implement a smoking ban, were more likely to provide substantial cessation assistance. Thus, hospitals that expressed concerns for employee health were willing to incur more expenses to help employees quit smoking, but the services provided had little if any effect on the overall perceived success of the policy. We note that due to the cross-sectional design, it is difficult to determine causality. Nonetheless, this is somewhat similar to the findings of Pederson, Bull, and Ashley, ${ }^{16}$ who found no difference in the prevalence of smoking cessation programmes, incentive programmes, or the provision of educational programmes in comparing workers in worksites with differences in legislative restrictions on smoking. 
INFLUENCES IN THE DECISION TO GO

SMOKE-FREE

Hospitals cited a variety of factors that influenced their decisions to go smoke-free. Most reported that a combination of internal and external factors contributed to their decision. Administrators who reported the involvement of four or more moderate-to-very important influences were more likely to view their hospital's policy as successful than those who cited fewer influences. Hospitals that reported a greater number of influences may have had an easier time enacting a smoking ban because there was more of a social norm supporting the policy. Hospitals that reported fewer influences may have been reacting more to outside regulation, making the process more difficult and less satisfactory.

As noted above, the JCAHO requirement was one of the major factors influencing many hospitals to go smoke-free. The other major factor was concern for employee health. Such sentiment is to be expected in a hospital community, where health maintenance is a principal goal. This factor may also be an issue of public image-a hospital that is concerned about the health of its employees will be viewed more favourably by the community than a hospital that is not. It is notable, however, that hospitals that expressed this concern did provide more substantial cessation assistance to employees. Although public image may have been a concern in many cases, there appears to have been a genuine interest in health issues. This is consistent with increased public concern over smoking, as illustrated by recent proliferation of state and local clean indoor air policies. $^{10}$

Public image and fire safety were next in importance in the decision to go smoke-free. These may be considered to be economic issues; a good public image would presumably help a hospital compete for "customers", whereas fire safety might involve both an enhanced public image and lower costs. Given the product sold by hospitals-health care services-it is important for hospitals to promote healthy practices.

\section{BARRIERS TO IMPLEMENTING A SMOKE-FREE} POLICY

There was no single dominant factor that affected hospitals' ability to go smoke-free. The top internal barrier, negative employee morale, is logically posed by the employees who smoke (we assume that employees who do not smoke would not create negative morale surrounding smoking bans in the workplace). It could be inferred that negative morale was lower when employee involvement in the planning process was greater. This result is logical, as smoking employees are the people adversely affected in the short term by a restrictive smoking policy. The top external barriers were lack of acceptance by patients and visitors.

MAJOR DETERMINANTS OF SUCCESS

A variety of factors were associated with exceeding JCAHO requirements. For example, we cannot discount that the political climate in non-tobacco states is more favourable to smoking restriction than in tobacco states; this could explain the correlation between high compliance and hospital location in a non-tobacco state. This is in contrast to our earlier work on overall compliance with JCAHO standards, where hospitals in non-tobacco states were more likely to be noncompliant than hospitals in tobacco-growing states. $^{7}$ We speculate that the social norm in tobacco states might pose problems with smoking bans in other industries as well. Thus, due to their unique social norms, hospitals in tobacco states are likely to comply with the standard, as found in our earlier study, but are not likely to exceed standard requirements.

Hospitals in MSAs were also more likely to be highly compliant. This may be related to the growing number of municipalities that place restrictions on smoking in public places. ${ }^{10}$ The social norm appears to be changing toward acceptance of smoking bans in many of our cities. Hospitals with fewer than 100 beds were more likely to exceed JCAHO requirements. We speculate that smaller hospitals with smaller bureaucracies experience fewer administrative barriers to policy implementation. Additionally, it may be possible that smaller organisations are able to come to a consensus about a smoking policy more quickly, and further recognise the possibility of expanding the policy. Large hospitals may simply feel that meeting the standard is all that can be accomplished given the cumbersome nature of large organisations.

Nineteen of the 20 children's hospitals in our sample exceeded the smoking ban requirements. Many of the restrictions that placed hospitals in the high-compliance category involved eliminating exceptions to the policy for patients. This might have simply been easier for children's hospitals, where providing children with policy exceptions, thereby allowing underage persons to smoke, could be seen as promoting illegal activity. In addition, social norms dictate that exposing children to secondhand smoke is less acceptable than similarly exposing adults. ${ }^{17-20}$

We speculate that treating other drug addictions or certain psychiatric conditions may take precedence over reducing cigarette smoking in hospitals with psychiatry or substance abuse units. Our earlier study of compliance with the JCAHO standards found that psychiatric hospitals were less likely to be in compliance than other types of hospitals. ${ }^{7}$ In the present study, we found that hospitals with psychiatry or substance abuse units were less likely to be highly compliant than hospitals without such units. Hospitals with these units, where the smoking policy was the same as that applied to the rest of the hospital, were even more likely to exceed JCAHO standards. The presence of patients with psychiatric problems or other addictions may make it difficult for a hospital to promote smoking restrictions that do not allow for any patient exceptions.

Finally, hospitals with unionised employees were more likely to be highly compliant than those with no union presence. This suggests 
that unions may actively promote smoking restrictions. Perhaps union presence is more common in metropolitan areas, where high compliance is more likely. This may illustrate a changing trend in society toward greater awareness of public and personal health.

\section{LIMITATIONS}

One possible limitation to our study is the question of external validity. It could be argued that hospitals represent a unique workplace. Workers in the healthcare industry have a greater awareness of health-related issues-for example, the hazards of cigarette smokingwhich may make it easier for hospitals to enact workplace smoking bans than other employers. It should be noted, however, that nurses, the largest single category of hospital employees, smoke at similar rates as the population at large. ${ }^{21}$ Despite the very low prevalence of smoking among physicians, hospital employees have similar smoking rates as the general population, making it appear unlikely that the hospital workforce is substantially different from other industries. ${ }^{22}$

Another possible limitation is that our data are from self-report. To address this issue, we compared the results of self-reported compliance with objective data from the JCAHO. The self-reported data correlate well with the JCAHO data- $96.6 \%$ of the hospitals responding to our survey were in compliance with the smoking ban standard, compared with $95.6 \%$ of hospitals surveyed by JCAHO in 1993 .

The use of a key informant in each hospital places a heavy emphasis on one individual's perception of the hospital's smoking policy development and implementation. Review of actual policies (manuscript in preparation) does validate respondents' perceptions. For example, $59.9 \%$ of respondents perceived that concern for the health of employees was a very important influence in the decision to go smoke-free. A similar proportion $(56.9 \%)$ of hospital smoking policies explicitly state that providing a healthy environment is a goal of the policy.

\section{Conclusions}

Smoking bans were successfully implemented in most American hospitals. The high level of compliance we observed was related to several factors, including overall support for smoking restrictions within the hospital industry, employee involvement in the policy-making process, social norms favouring smoking bans in the hospital environment, and semiregulation of the industry by the JCAHO. Rather than simply developing policies, other industries must view tobacco control as a process that includes policy development, rigid implementation, and inspection of institutions to determine compliance.

The importance of an external influence, however, may limit the abilities of other industries to develop smoking bans. For example, questions may arise regarding workplace inspection. Who will be responsible for inspection? How often should inspection take place? Many workplaces are subject to no such control. Replication of the hospital industry experience may not be feasible in workplaces where social norms discourage smoking bans.

Workplace smoking bans have been shown to reduce the overall smoking rate of hospital employees. ${ }^{8}$ Smoking restrictions may be a cost-effective way for employers to decrease healthcare costs, improve workplace safety, and improve productivity.

This study was funded by the Robert Wood Johnson Foundation's Tobacco Control Policy Program, Princeton, New Jersey (grant 22931)

1 US Centers for Disease Control and Prevention. Cigarette smoking-attributable mortality and years of potential life smoking-attributable mortality and years of potential

2 Wells AJ. Passive smoking as a cause of heart disease. $7 \mathrm{Am}$ Coll Cardiol 1994;24:546-54.

3 US Centers for Disease Control and Prevention. Medical care expenditures attributed to cigarette smoking-United States, 1993. MMWR 1994;43:469-72.

4 Mudarri DH. The costs and benefits of smoking restrictions: an assessement of the Smoke-Free Environment Act of 1993 (H.R. 3434). Washington, DC: US Environmental Protec(H.R. 3434). Washington, DC: US Environmental Protec-
tion Agency, Office of Air and Radiation, Indoor Air Division, 1994 .

5 American Hospital Association. 1992 Annual survey of hospitals data base. Chicago, Illinois: American Hospital Association, 1993.

6 US Joint Commission on Accreditation of Healthcare Organizations. Accreditation manual for hospitals. Oakbrook Terrace, Illinois: Joint Commission on Accreditation of Healthcare Organizations, 1992.

7 Longo DR, Brownson RC, Kruse RL. Smoking bans in U.S. hospitals: results of a national survey. $\mathscr{f} A M A$ 1995; 274:488-91.

8 Longo DR, Brownson RC, Johnson JC, et al. Hospital smoking bans and employee smoking behavior-results of a national survey. FAMA 1996;275:1252-7.

9 American Hospital Association. Hospital statistics, 19901991 edition. Data compiled from the American Hospital Association's 1989 Annual Survey of Hospitals. Chicago, Illinois: American Hospital Association, 1990.

10 Brownson RC, Eriksen MP, Davis RM, et al. Environmental tobacco smoke: health effects and policies to reduce exposure. Anпu Rev Public Health 1997;18:163-85.

11 Sorensen G, Rigotti N, Rosen A, et al. Effects of a worksite nonsmoking policy: evidence for increased cessation. $A m \mathcal{F}$ Public Health 1991;81:202-4.

12 Andrews JL, Jr. Reducing smoking in the hospital. An effective model program. Chest 1983;84:206-9.

13 Baile WF, Gibertini M, Ulschak F, et al. Impact of a hospital smoking ban: changes in tobacco use and employee attitudes. Addict Behav 1991;16:419-26.

14 Goldstein AO, Westbrook WR, Howell RE, et al. Hospital efforts in smoking control: remaining barriers and challenges. F Fam Pract 1992;34:729-34.

15 Rigotti NA, Pikl BH, Cleary P, et al. The impact of banning smoking on a hospital ward: acceptance, compliance, air quality and smoking behavior. Clin Res 1986;34:833A.

16 Pederson LL, Bull SB, Ashley MJ. Smoking in the workplace: do smoking patterns and attitudes reflect the legislative environment? Tobacco Control 1996;5:39-45.

17 Nelson DE, Giovino GA, Shopland DR, et al. Trends in cigarette smoking among U.S. adolescents, 1974 through 1991. Am $\mathcal{F}$ Public Health 1995;85:34-40.

18 Moss AJ, Allen KF, Giovino GA, et al. Recent trends in adolescent smoking, smoking-uptake correlates, and expectations about the future. Hyattsville, Maryland: National Center for 93-1250.)

19 Naeye RL. The duration of maternal cigarette smoking, fetal and placental disorders. Early Hum Dev 1979;3:22937.

20 US Department of Health and Human Services. Survey on tobacco use, 1991 - summary report. Atlanta, Georgia: Centers for Disease Control, 1991.

21 Nelson DE, Giovino GA, Emont SL, et al. Trends in cigarette smoking among U.S. physicians and nurses. fAMA 1994;271:1273-5.

22 Stillman FA, Hantula DA, Swank R. Creating a smoke-free hospital: attitudes and smoking behaviors of nurses and physicians. Am $\mathcal{F}$ Health Prom 1994;9:108-14. 